\title{
OPTIMALISASI PENGGUNAAN GATE TERMINAL 3 DOMESTIK BANDAR UDARA INTERNASIONAL SOEKARNO-HATTA DI MASA PANDEMI COVID-19
}

\author{
${ }^{1)}$ Dewi Handayani, ${ }^{2)}$ Muhammad Hammam Rassya, ${ }^{3)}$ Widi Hartono \\ 1)3) Dosen Program Studi Teknik Sipil Fakultas Teknik Universitas Sebelas Maret Surakarta \\ 2)Mahasiswa Program Studi Teknik Sipil Fakultas Teknik Universitas Sebelas Maret Surakarta \\ Fakultas Teknik Program Studi Teknik Sipil Universitas Sebelas Maret Surakarta, \\ Jln Ir. Sutami 36A, Surakarta. Email : hammamrassya@student.uns.ac.id
}

\begin{abstract}
COVID-19 Pandemic happened in Indonesia has affected the decline of airport passengers. The decline happened due to social distancing being applied in diminishing the COVID-19 spread. It is also affecting the decline of aircraft movement. Based on that condition, Terminal 3 Domestic Soekarno-Hatta International Airport needs to optimize its operations especially gate assignment because of being associated directly to passengers and aircraft movement. Therefore, the research is conducted to understand the optimization model of gate assignment during the COVID-19 Pandemic. This research uses primary data and secondary data. The primary data is the interview conducted with landside facility staff of Terminal 3 Domestic. The secondary data is cultivated data from PT. Angkasa Pura II (Persero). The research method is linear programming with the calculation using POM-QM for Windows 5 program. This research uses 18 variables which are the gate assignment frequency and 39 constraints. The result using linear programming method shows the optimized gate assignment frequency for passengers boarding. This is the frequency from every gate U11: 528 times, U12: 932 times, U13: 1080 times, U14: 1159 times, U15: 863 times, U16: 691 times, U17: 523 times, U18: 15 times, U19: 2266 times, U20: 545 times, U21: 0 times, U22: 197 times, U23: 5 times, U24: 84 times, U25: 0 time, U26: 163 times, U27: 0 time, dan U28: 74 times. This is the frequency of gate assignment during one year pandemic situation with social restriction measures being applied.
\end{abstract}

Keywords: Airport, COVID-19 Pandemic, Gate, Linear Programming, Optimization

\begin{abstract}
Abstrak
Kondisi Pandemi COVID-19 yang terjadi di Indonesia berdampak kepada penurunan jumlah penumpang di bandara. Penurunan ini terjadi karena pembatasan sosial yang berlaku dalam rangka memutus mata rantai penyebaran COVID-19. Penurunan jumlah penumpang juga berdampak kepada penurunan jumlah penerbangan. Sesuai dengan kondisi tersebut, Terminal 3 Domestik Bandar Udara Internasional Soekarno-Hatta perlu melakukan optimalisasi khususnya operasional penggunaan gate karena berhubungan langsung dengan jumlah penerbangan dan penumpang. Oleh karena itu, dilakukan penelitian untuk mengetahui model optimalisasi penggunaan gate dalam menghadapi Pandemi COVID-19. Dalam penelitian ini menggunakan data primer dan data sekunder. Data primer berupa wawancara yang dilakukan dengan staff landside facility Terminal 3 Domestik dan data sekunder berupa data olahan yang didapat dari pihak PT. Angkasa Pura II (Persero). Metode yang digunakan adalah metode program linier dengan perhitungan menggunakan program POM-QM for Windows 5. Penelitian ini menggunakan 18 variabel yang berupa frekuensi penggunaan gate dan 39 fungsi kendala (constraints). Hasil penelitian menggunakan metode program linier menghasilkan frekuensi optimal gate digunakan untuk proses boarding penumpang. Ini adalah tiap-tiap frekuensi dari penggunaan gate U11: 528 kali, U12: 932 kali, U13: 1080 kali, U14: 1159 kali, U15: 863 kali, U16: 691 kali, U17: 523 kali, U18: 15 kali, U19: 2266 kali, U20: 545 kali, U21: 0 kali, U22: 197 kali, U23: 5 kali, U24: 84 kali, U25: 0 kali, U26: 163 kali, U27: 0 kali, dan U28: 74 kali. Frekuensi tersebut merupakan penggunaan selama satu tahun situasi pandemi dengan penerapan pembatasan pergerakan masyarakat.
\end{abstract}

Kata Kunci : Bandara, Gate, Optimalisasi, Pandemi COVID-19, Program Linier

\section{PENDAHULUAN}

Bandar udara merupakan infrastruktur penting dalam penyelenggaraan penerbangan di Indonesia. Bandar Udara adalah suatu area atau kawasan baik di darat maupun di perairan dengan batas tertentu yang difungsikan sebagai tempat lepas landas dan mendarat pesawat terbang, menaikkan dan menurunkan penumpang, loading barang, dan tempat perpindahan intra dan antar moda transportasi, yang memiliki fasilitas keselamatan dan keamanan penerbangan yang lengkap, serta fasilitas pokok dan fasilitas penunjang lainnya. Jumlah penumpang dan jumlah penerbangan merupakan parameter penting dalam operasional sebuah bandar udara.

Pada kuartal II tahun 2020, terjadi situasi Pandemi COVID-19 di Indonesia dan sudah memakan korban jiwa sebanyak 38.573 orang hingga 15 Maret 2021 (Kemenkes, 2021). Sesuai dengan Data BPS yang dikutip dari Merdeka.com (2020), terjadi penurunan jumlah penumpang sebesar $90 \%$ karena kondisi pandemi. Penurunan ini 
mengakibatkan penerbangan menjadi lebih sepi dari tahun sebelumnya. Salah satu bandara yang terdampak adalah Bandar Udara Internasional Soekarno-Hatta. Bandara ini memiliki tiga terminal yang salah satunya adalah Terminal 3. Terminal 3 menampung kapasitas pergerakan hingga 25 juta penumpang. Pada saat kondisi pandemi dengan peraturan yang berlaku, kapasitas penumpang dibatasi hingga 50\% dari kapasitas normal. Terminal 3 memiliki jumlah gate sebanyak 14 gate di bagian domestik (travel.kompas.com, 2019). Sesuai penjelasan sebelumnya, operasional bandara khususnya penggunaan gate menjadi terbatas karena terjadinya pandemi.

Penelitian ini memiliki kesamaan topik optimalisasi bandar udara yang diteliti oleh Sari (2016), Nugraha (2016), Sabur (2019), Paendong et al. (2020), Xiao et al. (2020), Yocing et al. (2020). Penelitian ini bertujuan untuk mendapatkan penggunaan gates yang optimal di Terminal 3 Domestik Bandar Udara Internasional Soekarno-Hatta. Metode yang digunakan sama dengan Yocing, dkk (2020) yaitu metode program linier. Penelitian ini memiliki objek yang sama dengan Pradana et al. (2017) yaitu gates penumpang. Variabel-variabel yang digunakan pada penelitian ini merujuk pada hasil penelitian Wirasinghe \& Bandara (1990), Sari (2016), Nugraha (2016), Pradana et al. (2017), Aditya (2019), Setiawan (2019), Sabur (2019), Paendong et al. (2020), Xiao et al. (2020), Yocing et al. (2020) yaitu jumlah penumpang, jumlah pergerakan pesawat, jumlah gate, gate occupancy time, kapasitas apron, kapasitas ruang tunggu, jadwal penerbangan, dan biaya operasional penggunaan gates. Hal spesifik dalam penelitian ini adalah penelitian ini dilakukan di masa Pandemi COVID-19 .

Untuk itu, penelitian ini bertujuan untuk mengetahui model optimalisasi penggunaan gate dalam menghadapi Pandemi COVID-19 di Bandar Udara Internasional Soekarno-Hatta khususnya Terminal 3 Domestik dengan menggunakan metode Program Linear.

\section{METODE}

\section{Manajemen Operasional Bandara}

Bandara merupakan poin keberangkatan dan pemberhentian dari sebuah perjalanan udara. Pada pelaksanaan operasional, bandara harus memiliki fasilitas untuk pesawat mendarat dan lepas landas. Di antara kedua operasional tersebut, pesawat perlu menurunkan dan menaikkan muatan seperti penumpang dan kru sehingga terbentuk sebuah sistem operasional bandara yang terbagi menjadi fungsi sisi udara dan sisi darat. Fungsi tersebut menunjukkan bahwa setelah sebuah penerbangan mendekat dan mendarat, pesawat menggunakan landasan pacu, taxiway, dan apron sebelum berhenti di posisi parking, yang mana proses penurunan muatan terjadi melalui terminal menuju pintu keluar. Penumpang yang akan berangkat berjalan dari sisi darat menuju gates keberangkatan.

\section{Metode Optimalisasi}

Berlianty dan Arifin (2010) mengatakan bahwa optimasi adalah proses pencarian satu atau lebih penyelesaian yang berhubungan dengan nilai-nilai dari satu atau lebih fungsi objektif pada suatu masalah sehingga diperoleh satu nilai optimal. Persoalan optimalisasi meliputi optimalisasi dengan kendala dan optimalisasi tidak dengan kendala. Dalam optimalisasi tidak dengan kendala, faktor-faktor yang menjadi kendala terhadap fungsi tujuan diabaikan sehingga tidak terdapat batasan-batasan dalam menentukan harga maksimal atau minimal terhadap berbagai pilihan variabel $\mathrm{X}$ yang tersedia. Dalam optimalisasi dengan kendala, faktor-faktor yang menjadi kendala pada fungsi tujuan diperhatikan karena berperan serta dalam menentukan nilai maksimal maupun minimal.

\section{Metode Program Linier}

Pemrograman Linear atau Linear Programming (LP) adalah salah satu metode matematika yang digunakan untuk penyelesaian masalah optimalisasi dalam mencari solusi optimal dengan fungsi objektif dan fungsi kendala yang berbentuk fungsi linear dari variabel keputusan yang linear. Haming dkk. (2017: 194) menuliskan bahwa goal programming adalah bagian dari salah satu optimasi multi objektif, yang mana juga bagian dari Multi-Criteria Decision Analysis (MCDA). Penyelesaian masalah dengan fungsi tujuan dan fungsi kendala dalam program linier bisa menggunakan dua metode, yakni metode grafik dan metode simpleks.

Penelitian ini menggunakan metode Program Linier (LP) menggunakan Program POM-QM untuk Windows 5. Terdapat 3 faktor harus ditentukan terlebih dahulu dalam penyelesaian masalah menggunakan metode program linier, yaitu variabel keputusan, fungsi tujuan, dan fungsi kendala. 


\section{Variabel Keputusan}

Variabel yang digunakan pada penelitian ini adalah frekuensi penggunaan gate yang tersedia di Terminal 3 Domestik selama satu tahun. Variabel keputusan dinyatakan dengan X. Sebagai contoh, X1 adalah penggunaan gate 11 selama satu tahun. Variabel yang digunakan adalah $\mathrm{X}_{1}-\mathrm{X}_{18}$ yang mewakilkan frekuensi penggunaan gate $11-18$.

\section{Fungsi Tujuan}

Fungsi tujuan yang digunakan pada penelitian ini adalah sebagai berikut:

$$
z=C_{1} X_{1}+C_{2} X_{2}+C_{3} X_{3}+\ldots+C_{18} X_{18} \ldots \ldots \ldots \ldots \text { [1] }
$$

Keterangan :

$\mathrm{z} \quad$ = fungsi tujuan biaya operasional yang diminimumkan,

$\mathrm{C}=$ biaya operasional setiap satu kali gate dibuka,

$\mathrm{X}=$ frekuensi penggunaan gate yang tersedia di Terminal 3 Domestik selama satu tahun.

\section{Fungsi Kendala}

Fungsi kendala yang digunakan pada penelitian ini adalah sebagai berikut:

$a_{1} X_{1}+a_{2} X_{2}+a_{3} X_{3}+\ldots+a_{18} X_{18} \leq$ Jumlah Penumpang... [2]

$b_{1} X_{1}+b_{2} X_{2}+b_{3} X_{3}+\ldots+b_{18} X_{18} \leq$ Jumlah Penumpang.. [3]

$x_{1}+x_{2}+x_{3}+x_{4}+\ldots+x_{18} \geq$ Kapasitas Apron

$x_{1}, x_{2}, x_{3}, \ldots, x_{4} \geq$ Jumlah penggunaan gate selama 2020 [5]

$x_{1}, x_{2}, x_{3}, \ldots, x_{4} \leq$ Kapasitas gate maksimal per hari selama satu tahun [6]

Keterangan :

$\mathrm{a} \quad=$ nilai koefisien jumlah pesawat yang dapat dilayani setiap gate

$\mathrm{b}=$ nilai koefisien jumlah kapasitas ruang tunggu setiap gate

\section{HASIL DAN PEMBAHASAN}

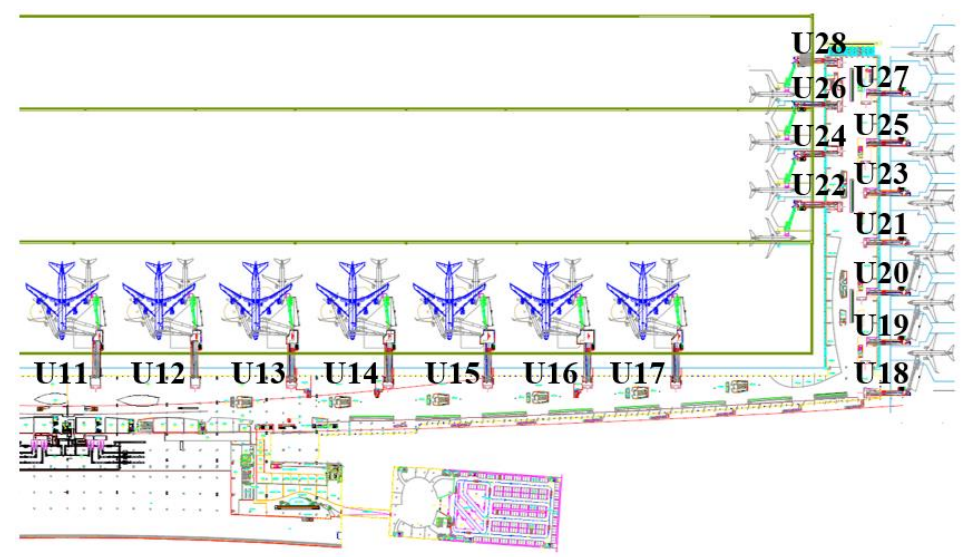

Gambar 1. Denah gate Terminal 3 Domestik Bandara Internasional Soekarno-Hatta

Gambar 1 merupakan tata letak dan denah dari gate yang tersedia di Terminal 3 Domestik Bandara Internasional Soekarno-Hatta. Penggunaan gate tersebut merupakan objek dari penelitian ini.

\section{Model Optimalisasi}

Model optimalisasi yang digunakan adalah fungsi tujuan dan fungsi kendala. Fungsi tersebut terdiri dari koefisien dan variabel keputusan. Koefisien tersebut ditentukan berdasarkan data yang diperoleh. Pada perhitungan optimalisasi penggunaan gate ini, koefisien yang digunakan adalah biaya operasional setiap satu kali penggunaan gate. Fungsi tujuan mengacu kepada persamaan [1] sehingga dapat dilihat sebagai berikut: 


$$
\begin{aligned}
& Z=1996443 X_{1}+188323 X_{2}+188323 X_{3}+188323 X_{4}+192237 X_{5}+194340 X_{6}+181580 X_{7}+140835 X_{8}+131990 X_{9}+ \\
& 131990 X_{10}+131990 X_{11}+131990 X_{12}+131990 X_{13}+131990 X_{14}+131990 X_{15}+131990 X_{16}+131990 X_{17} \\
& +1331990 X_{18}
\end{aligned}
$$

Fungsi kendala yang digunakan pada optimalisasi penggunaan gate di Terminal 3 Domestik adalah sebagai berikut.

\section{a. Fungsi kendala terhadap Jumlah Penerbangan}

Fungsi kendala terhadap jumlah penerbangan merupakan fungsi maksimum jumlah penerbangan yang dilayani selama tahun 2020 yaitu 68.726 penerbangan. Selama masa pandemi, pesawat yang beroperasi sebagian besar adalah pesawat narrow-body atau berbadan kecil sehingga diasumsikan setiap gate dapat digunakan pada kapasitas maksimum. Fungsi ini menggunakan koefisien dari jumlah pesawat yang dapat dilayani setiap gate-nya. Terminal 3 Domestik memiliki dua tipe gate berdasarkan jumlah pesawat yang dapat dilayani. Gate U11-U17 dapat melayani dua pesawat narrow-body secara kapasitas penuh. Untuk itu, koefisien angka 2 digunakan pada variabel X1 sampai dengan X7. Gate U18-U28 hanya dapat melayani satu pesawat narrow-body secara kapasitas penuh, sehingga koefisien angka 1 digunakan pada variabel X8 sampai dengan X18. Fungsi kendala mengacu kepada persamaan [2] sehingga dapat dilihat sebagai berikut:

$$
\begin{aligned}
& 2 X_{1}+2 X_{2}+2 X_{3}+2 X_{4}+2 X_{5}+2 X_{6}+2 X_{7}+X_{8}+X_{9}+X_{10}+X_{11}+X_{12}+X_{13} \\
& +X_{14}+X_{15}+X_{16}+X_{17}+X_{18} \leq 68726 \ldots \ldots \ldots \ldots \ldots . .
\end{aligned}
$$

\section{b. Fungsi kendala terhadap Jumlah Penumpang}

Fungsi kendala terhadap jumlah penumpang merupakan fungsi maksimum jumlah penumpang yang dilayani selama tahun 2020 yaitu 4.989.248 penumpang. Dalam pendekatan perhitungan biaya operational gate, operational boarding lounge merupakan salah satu komponen yang dihitung pada saat melayani penumpang. Oleh karena itu, fungsi ini menggunakan koefisien dari jumlah kapasitas kursi yang tersedia di setiap gate (kapasitas boarding lounge). Asumsi yang digunakan adalah setiap kursi di ruang tunggu digunakan oleh tiap-tiap penumpang. Jumlah kapasitas kursi yang tersedia di setiap gate dapat dilihat pada tabel 1.

Tabel 1. Jumlah kapasitas kursi di gate

\begin{tabular}{cccccc}
\hline Gate & $\begin{array}{c}\text { Kapasitas } \\
\text { Kursi }\end{array}$ & Gate & $\begin{array}{c}\text { Kapasitas } \\
\text { Kursi }\end{array}$ & Gate & $\begin{array}{c}\text { Kapasitas } \\
\text { Kursi }\end{array}$ \\
\hline U11 & 229 & U17 & 69 & U23 & 95 \\
U12 & 191 & U18 & 93 & U24 & 95 \\
U13 & 152 & U19 & 70 & U25 & 83 \\
U14 & 209 & U20 & 71 & U26 & 99 \\
U15 & 203 & U21 & 133 & U27 & 93 \\
U16 & 141 & U22 & 82 & U28 & 71 \\
\hline
\end{tabular}

Pada tahun 2020, terminal 3 domestik melayani jumlah penerbangan sebanyak 4.989 .248 penumpang. Fungsi kendala mengacu kepada persamaan [3] sehingga dapat dilihat sebagai berikut:

$$
\begin{aligned}
& 229 X_{1}+191 X_{2}+152 X_{3}+209 X_{4}+203 X_{5}+141 X_{6}+69 X_{7}+93 X_{8}+70 X_{9}+71 X_{10}+133 X_{11}+82 X_{12}+95 X_{13}+95 X_{14} \\
& +83 X_{15}+99 X_{16}+93 X_{17}+71 X_{18} \leq 68726 \ldots \ldots \ldots .[9]
\end{aligned}
$$

\section{c. Fungsi kendala terhadap Kapasitas Apron}

Pada terminal 3, setiap gate memiliki kapasitas apronnya masing-masing sehingga fungsi kendala tidak dapat diwakilkan hanya dengan kapasitas ruang tunggu. Oleh karena itu, diperlukan fungsi kendala terhadap kapasitas apron dengan menggunakan asumsi bahwa apron selalu digunakan minimal satu kali sehari selama satu tahun. Perhitungan tersebut adalah sebagai berikut:

$$
C_{a}=\left(C_{1} Y_{1}+C_{2} Y_{2}\right) \times 365
$$


Ca adalah kapasitas apron; C1 adalah total nilai pesawat yang sanggup dilayani oleh gate U11-U17; C2 adalah total nilai pesawat yang sanggup dilayani oleh gate U18-U28; dan Y adalah Jumlah gate. Perhitungan kapasitas apron adalah sebagai berikut:

$$
\begin{aligned}
& C_{a}=(2 \times 7+1 \times 11) \times 365 \\
& C_{a}=9125 \text { pesawat }
\end{aligned}
$$

Fungsi kendala terhadap kapasitas apron mengacu kepada persamaan [11] sehingga dapat dilihat sebagai berikut:

$X_{1}+X_{2}+X_{3}+X_{4}+X_{5}+X_{6}+X_{7}+X_{8}+X_{9}+X_{10}+X_{11}+X_{12}+X_{13}+X_{14}$

$+X_{15}+X_{16}+X_{17}+X_{18} \leq 69125$

\section{d. Fungsi minimum penggunaan gate pada tahun 2020}

Fungsi minimum penggunaan gate pada tahun 2020 merupakan fungsi minimum yang nilainya didapatkan dari perhitungan data yang diperoleh. Data yang digunakan adalah data rata-rata penggunaan harian. Rata-rata penggunaan harian diperoleh dari data lapangan PT Angkasa Pura II (Persero) dengan periode 29 April - 12 Juli 2020. Data tersebut diambil rata-rata penggunaan untuk dapat dihitung penggunaannya selama satu tahun. Berikut merupakan rumus perhitungan penggunaan selama satu tahun:

$$
f_{\text {tahunan }}=f_{\text {harian }} \times 365 \text {. }
$$

Keterangan :

$f_{\text {tabunan }}=$ jumlah penggunaan gate selama satu tahun

$f_{\text {barian }}=$ rata-rata penggunaan gate per hari.

Contoh perhitungan untuk salah satu penggunaan gate yaitu gate U11 adalah sebagai berikut:

$$
\begin{aligned}
f_{\text {tahunan }} & =1,446 \times 365 \\
& =528 \mathrm{kali}
\end{aligned}
$$

\begin{tabular}{|c|c|c|c|c|c|c|c|c|}
\hline Gate & $\begin{array}{c}\text { Rata-rata } \\
\text { penggunaa } \\
\text { n harian }\end{array}$ & $\begin{array}{c}\text { Penggunaa } \\
\text { n selama } \\
\text { satu tahun }\end{array}$ & Gate & $\begin{array}{c}\text { Rata-rata } \\
\text { penggunaan } \\
\text { harian }\end{array}$ & $\begin{array}{c}\text { Penggunaan } \\
\text { selama satu } \\
\text { tahun }\end{array}$ & Gate & $\begin{array}{l}\text { Rata-rata } \\
\text { pengguna } \\
\text { an harian }\end{array}$ & $\begin{array}{c}\text { Penggun } \\
\text { aan } \\
\text { selama } \\
\text { satu } \\
\text { tahun } \\
\end{array}$ \\
\hline U11 & 1,446 & 528 & U17 & 1,432 & 523 & $\mathrm{U} 23$ & 0,014 & 5 \\
\hline U12 & 2,554 & 933 & U18 & 0,041 & 15 & U24 & 0,229 & 84 \\
\hline U13 & 2,959 & 1080 & U19 & 0,014 & 5 & U25 & 0,000 & 0 \\
\hline U14 & 3,176 & 1159 & U20 & 0,068 & 25 & U26 & 0,446 & 163 \\
\hline U15 & 2,365 & 863 & U21 & 0,000 & 0 & $\mathrm{U} 27$ & 0,000 & 0 \\
\hline U16 & 1,892 & 690 & U22 & 0,541 & 197 & U28 & 0,203 & 74 \\
\hline
\end{tabular}

Rekapitulasi perhitungan penggunaan gate selama satu tahun dapat dilihat lebih lengkap pada tabel 2.

Tabel 2. Rekapitulasi perhitungan penggunaan gate

Sesuai dengan tabel 2, gate yang paling sering digunakan adalah gate U14 sebanyak 1159 kali selama satu tahun penggunaan di masa pandemi dengan diberlakukannya pembatasan sosial. Gate U21, U25, dan U26 tidak digunakan selama satu tahun masa pandemi. Dari hasil perhitungan, didapatkan fungsi-fungsi kendala minimum dari penggunaan gate adalah sebagai berikut:

$X_{1} \geq 528 ; X_{2} \geq 932 ; X_{3} \geq 1080 ; X_{4} \geq 1159 ; X_{5} \geq 863 ; X_{6} \geq 691 ; X_{7} \geq 523 ; X_{8} \geq 15 ; X_{9} \geq 5 ; X_{10} \geq 25 ; X_{11} \geq 0 ; X_{12} \geq 197 ;$ $\mathrm{X}_{13} \geq 5 ; \mathrm{X}_{14} \geq 84 ; \mathrm{X}_{15} \geq 0 ; \mathrm{X}_{16} \geq 163 ; \mathrm{X}_{17} \geq 0 ; \mathrm{X}_{18} \geq 74$

\section{e. Fungsi maksimum penggunaan gate selama satu tahun}

Fungsi maksimum penggunaan gate selama satu tahun merupakan fungsi maksimum yang nilainya didapatkan dari frekuensi maksimal penggunaan gate per hari dalam satu tahun dengan kapasitas pesawat setiap gate-nya. Penggunaan dikurangi 50\% karena kondisi pandemi agar gate dapat disanitasi sebelum digunakan penerbangan selanjutnya. Rumus perhitungan nilai tersebut adalah sebagai berikut: 
$F_{\text {tahunan }}=\left(\frac{24}{T} \times C_{n} \times 365\right) \times 50 \%$

$F_{\text {tabun }}$ adalah penggunaan gate maksimal selama satu tahun; $T$ adalah waktu pemakaian gate; dan $C_{n}$ adalah jumlah pesawat setiap gate. Perhitungan jumlah maksimum penggunaan gate selama satu tahun adalah sebagai berikut. Gate U11-U17:

$$
\begin{aligned}
F_{\text {tahunan }} & =\left(\frac{24}{1,93} \times 2 \times 365\right) \times 50 \% \\
& =4531 \mathrm{kali}
\end{aligned}
$$

Gate U18-U28:

$$
\begin{aligned}
F_{\text {tahuman }} & =\left(\frac{24}{1,93} \times 2 \times 365\right) \times 50 \\
& =2266 \mathrm{kali}
\end{aligned}
$$

Fungsi-fungsi kendala maksimum yang digunakan adalah sebagai berikut:

$X_{1} ; X_{2} ; X_{3} ; X_{4} ; X_{5} ; X_{6} ; X_{7} \leq 4531$

$X_{8} ; X_{9} ; X_{10} ; X_{11} ; X_{12} ; X_{13} ; X_{14} ; X_{15} ; X_{16} ; X_{17} ; X_{18} \leq 2266[15]$

\section{Perhitungan Metode Program Linier}

Dari hasil identifikasi model optimalisasi, ditemukan bahwa variabel yang digunakan sebanyak 18 variabel dengan 39 constraints (fungsi kendala). Untuk itu, agar perhitungan lebih akurat, digunakan Program POM-QM for Windows 5. Program POM-QM for Windows 5 merupakan sebuah program komputasi yang digunakan dalam memecahkan permasalahan kehidupan sehari-hari. Salah satu fungsinya adalah linear programming.

Hasil perhitungan program menunjukkan setiap variabel memiliki angka yang berbeda. Angka tersebut mempunyai makna sebagai jumlah frekuensi penggunaan gate di Terminal 3 Domestik Bandara Internasional Soekarno-Hatta selama satu tahun. Hasil angka X1 yaitu 528 yang berarti gate U11 digunakan sebanyak 528 kali selama satu tahun. Lebih lengkapnya, setiap nilai $\mathrm{X}$ dapat dilihat sebagai berikut:

$\mathrm{X}_{1}=528 ; \mathrm{X}_{2}=932 ; \mathrm{X}_{3}=1080 ; \mathrm{X}_{4}=1159 ; \mathrm{X}_{5}=863 ; \mathrm{X}_{6}=691 ; \mathrm{X}_{7}=523 ; \mathrm{X}_{8}=15 ; \mathrm{X}_{9}=2266 ; \mathrm{X}_{10}=545 ; \mathrm{X}_{11}=0 ; \mathrm{X}_{12}=197 ;$ $\mathrm{X}_{13}=5 ; \mathrm{X}_{14}=84 ; \mathrm{X}_{15}=0 ; \mathrm{X}_{16}=163 ; \mathrm{X}_{17}=0 ; \mathrm{X}_{18}=74$.

Setelah mendapatkan nilai X dari perhitungan program, disubtitusikan ke dalam persamaan fungsi tujuan [7].

$$
\begin{aligned}
& Z=(1996443 \times 528)+(188323 \times 932)+(188323 \times 1080)+(188323 \times 1159)+(192237 \times 863)+(194340 \times 691)+(181580 \times 523) \\
& +(140835 \times 15)+(131990 \times 2266)+(131990 \times 545)+(131990 \times 0)+(131990 \times 197)+(131990 \times 5)+(131990 \times 84) \\
& (131990 \times 0)+(131990 \times 163)+(131990 \times 197)+(131990 \times 84) \\
& \quad=1538217000
\end{aligned}
$$

Dari perhitungan fungsi tujuan, didapatkan biaya operasional minimum selama masa pandemi adalah sebesar Rp1.538.217.000,00.

\section{HASIL DAN PEMBAHASAN}

Berdasarkan data yang diperoleh, gate U19 merupakan gate tersibuk selama masa pandemi dikarenakan biaya operasionalnya yang murah dan lokasinya juga tidak terlalu jauh dari tempat check-in penumpang. Jumlah pembukaan gate berguna dalam meminimalkan pengeluaran pengelolaan bandara. Rekomendasi ini didasarkan data yang terjadi selama masa pandemi 29 April sampai dengan 12 Juli 2020 dan mengasumsikan operasional ruang tunggu yang dapat digunakan maksimal hanya 50\% dari kapasitas normal.

Hasil analisis penelitian optimalisasi penggunaan gate yang dilakukan ini tidak banyak berbeda dengan Wiransinghe dan Bandara pada tahun 1990, yaitu merekomendasi jumlah pembukaan beberapa gate. Wiransinghe dan Bandara (1990) juga melakukan estimasi posisi gate bandara terhadap biaya minimal, dengan perbedaan metode analisis, Wirasinghe \& Bandara (1990) adalah solusi perkiraan closed-form matematis sedangkan metode penelitian ini adalah program linier. Variabel yang digunakan penelitian ini hampir sama dengan Wirasinghe \& Bandara (1990), 
hanya satu variabel yang berbeda yaitu biaya keterlambatan penumpang. Untuk itu disarankan untuk penelitian lebih lanjut dapat digunakan dengan menambah biaya keterlambatan penumpang.

Demikian halnya dengan hasil penelitian Sari (2016) yang meneliti tentang optimalisasi parking stand dengan menggunakan metode antrian dengan tingkat probabilitas 1 dan tingkat utilisasi serta membagi 2 klasifikasi berdasarkan waktu; yaitu weekend dan weekday. Penelitian tersebut menjadi referensi karena variabel yang digunakan sama dengan variabel pada penelitian ini. Variabel seperti jumlah penumpang dan jumlah penerbangan menjadi fungsi kendala pada perhitungan metode program linier. Sari (2016) lebih menitikberatkan pada objek parking stand (air-side) yang tidak saat pandemi, sedangkan penelitian ini dengan objek gate (land-side) saat pandemi. Oleh karena itu, dapat disarankan untuk meneliti optimalisasi atau pun utilisasi parking stand pada gate terminal 3 domestik selama masa pandemi.

Nugraha (2016) dalam meneliti optimalisasi gate di Bandara Halim Perdanakusuma juga menggunakan variabelvariabel yang sama, hanya saja pendekatan pada tingkat utilisasi gate. Oleh karena itu, untuk penelitian selanjutnya dapat disarankan untuk menggunakan metode analisis dengan pendekatan tingkat utilisasi gate selama masa pandemi.

Penelitian oleh Aditya (2019), Sabur (2019), dan Paendong et al. (2020) tentang evaluasi dan optimalisasi kapasitas apron juga digunakan sebagai tinjauan pada penelitian ini karena variabel yang digunakan sama. Penelitian tersebut mendapatkan hasil tentang kapasitas apron yang juga digunakan sebagai fungsi kendala pada penelitian ini. Setiawan (2019) juga melakukan analisis kapasitas apron dan ruang tunggu. Didapatkan analisis ruang tunggu berupa jumlah tempat duduk yang juga digunakan sebagai koefisien fungsi kendala jumlah penumpang pada penelitian ini.

Hasil penelitian ini mendukung penelitian Xiao et al. (2020) yaitu untuk mendapatkan total cost yang minimal dan jumlah gate yang optimal, meskipun dengan metode analisis dan pendekatan biaya yang berbeda. Untuk itu, disarankan untuk penelitian selanjutnya dapat menambahkan perhitungan biaya seperti biaya transfer penumpang, biaya flight dwelling, dan biaya penggunaan gate. Perhitungan biaya tersebut dapat menambahkan keakuratan dari hasil penelitian tentang optimalisasi gate.

\section{SIMPULAN}

Model optimalisasi yang digunakan pada perhitungan optimalisasi penggunaan gate Terminal 3 Domestik Bandara Internasional Soekarno-Hatta adalah fungsi tujuan dari metode program linier. Fungsi tujuan tersebut adalah sebagai berikut:

$$
\begin{aligned}
& Z=1996443 X_{1}+188323 X_{2}+188323 X_{3}+188323 X_{4}+192237 X_{5}+194340 X_{6}+181580 X_{7}+140835 X_{8}+131990 X_{9}+ \\
& 131990 X_{10}+131990 X_{11}+131990 X_{12}+131990 X_{13}+131990 X_{14}+131990 X_{15}+131990 X_{16}+131990 X_{17} \\
& +1331990 X_{18}
\end{aligned}
$$

Yang mana, $\mathrm{Z}$ adalah fungsi tujuan biaya operasional yang diminimumkan; $\mathrm{X}_{\mathrm{n}}$ adalah jumlah frekuensi penggunaan gate dalam waktu satu tahun.

Berdasarkan hasil perhitungan menggunakan metode program linier, frekuensi optimal penggunaan gate selama masa pandemi dengan penerapan pembatasan pergerakan masyarakat didapatkan sebagai berikut:

$$
\begin{aligned}
& \mathrm{U} 11=528 \mathrm{kali} \quad \mathrm{U} 14=1159 \mathrm{kali} \mathrm{U} 17=523 \mathrm{kali} \quad \mathrm{U} 20=545 \mathrm{kali} \quad \mathrm{U} 23=5 \mathrm{kali} \quad \mathrm{U} 26=163 \mathrm{kali} \\
& \mathrm{U} 12=932 \mathrm{kali} \quad \mathrm{U} 15=863 \mathrm{kali} \quad \mathrm{U} 18=15 \mathrm{kali} \quad \mathrm{U} 21=0 \text { kali } \quad \mathrm{U} 24=84 \mathrm{kali} \quad \mathrm{U} 27=0 \text { kali } \\
& \mathrm{U} 13=1080 \mathrm{kali} \quad \mathrm{U} 16=690 \mathrm{kali} \quad \mathrm{U} 19=2266 \mathrm{kali} \text { U22 }=197 \mathrm{kali} \quad \mathrm{U} 25=0 \text { kali } \quad \text { U28 }=74 \mathrm{kali}
\end{aligned}
$$

\section{REKOMENDASI}

Rekomendasi yang dapat diberikan pada penelitian berikutnya adalah sebagai berikut:

1. Dikarenakan keterbatasan data sekunder yang diperoleh, diharapkan penelitian selanjutnya dapat menggunakan data selama satu tahun penuh agar hasil yang didapat lebih akurat.

2. Menggunakan fungsi kendala tambahan seperti jarak antar gate dan waktu tempuh penumpang dari landside menuju airside. 
3. Menambahkan faktor perhitungan biaya operasional selain biaya operasional listrik dan man power. Faktorfaktor tersebut dapat termasuk biaya perawatan gedung, biaya perawatan garbarata, dan sebagainya.

4. Penelitian selanjutnya dapat menambahkan perhitungan biaya seperti biaya transfer penumpang, biaya flight dwelling, dan biaya penggunaan gate.

5. Pada studi kasus ini, satu gate memiliki satu ruang tunggu yang mana salah satu komponen biaya optimalisasi didasarkan dengan jumlah kapasitas kursi yang terisi di ruang tunggu sebagai fungsi kendala terhadap jumlah penumpang, akan tetapi mengabaikan jumlah kursi pesawat yang kemungkinan memiliki nilai yang lebih kecil dari ruang tunggu. Oleh karena itu, penelitian selanjutnya dapat diperbandingkan terlebih dahulu antara kapasitas ruang tunggu dan kapasitas kursi pesawat yang mana yang lebih mewakili sebagai fungsi kendala terhadap jumlah penumpang

\section{UCAPAN TERIMA KASIH}

Penulis mengucapkan terima kasih yang sebanyak-banyaknya kepada pembimbing yaitu Ibu Dr. Dewi Handayani, S.T., M.T. dan Bapak Widi Hartono, S.T., M.T yang telah mengajarkan ilmu dan arahan pada proses penulisan jurnal ini. Rasa terima kasih juga penulis ucapkan kepada PT. Angkasa Pura II (Persero) yang telah memberikan otorisasi penggunaan data sehingga penelitian ini dapat dilaksanakan.

\section{REFERENSI}

Ashford, et al., 2012, “Airport Operations Third Edition”, The McGraw-hill Companies, Inc. New York City

Aditya, F., 2019, "Evaluasi Kapasitas Apron Pada Bandar Udara Internasional I Gusti Ngurah Rai Bali", Prosiding Seminar Intelektual Muda, pp. 315-320. https://trijurnal.lemlit.trisakti.ac.id/sim/article/view/5973

Berlianty, I., \& Arifin, M., 2010. "Teknik-teknik Optimasi Heuristic", Graha Ilmu, Yogyakarta.

Chaerani, Diah., Lesmana, Eman., Hertini, Elis., 2019. "Pemrograman Linear". Bitread. Bandung

Haming; Murdifin H., Ramlawati., Suriyanti., dan Imaduddin., 2017, "Operation Research: Teknik Pengambilan Keputusan Optimal". Bumi Aksara, Jakarta.

Herjanto, Eddy., 2007, "Manajemen Operasi", Grasindo. Jakarta

Nugraha, Astario A. 2016. "Optimalisasi Parking Stand terhadap Kapasitas Apron pada saat Jam Sibuk di Bandar Udara Halim Perdanakusuma PT Angkasa Pura II (Persero) pada Tahun 2015", Skripsi, Sekolah Tinggi Manajemen Transportasi Trisakti. Jakarta

Paendong, A. A. V., Lefrandt, L. I. R., \& Rumayar, A. L. E., 2020, "Analisis Kapasitas dan Optimalisasi Apron Bandar Udara Internasional Sam Ratulangi Manado", Jurnal Sipil Statik, Vol 8 No 2, pp. 176.

Pradana, A. N., Ahyudanari, E., \& Istiar, I., 2017, "Evaluasi Ketersediaan Gate Di Terminal 3 Ultimate Bandar Udara Internasional Soekarno-Hatta", Jumal Teknik ITS, Vol 6 No 1. https://doi.org/10.12962/j23373539.v6i1.22032

Sabur, F., 2019, "The Optimization of Apron Capacity in Blimbingsari Banyuwangi Airport", Vol 16 No 5, pp. 29-35. https://doi.org/10.9790/1684-1605022935

Sari, M., 2016, "Optimalisasi Parking Stand di Terminal 2F Bandara Soekarno-Hatta Tahun 2015", Jurnal Manajemen Bisnis Transportasi Dan Logistik, Vol 3 No 1, pp. 111-116.

Setiawan, D., 2019, "Analisis Kapasitas Apron dan Ruang Tunggu Keberangkatan Penumpang Pesawat pada New Yogyakarta International Airport", Semesta Teknika, Vol 22 No. 1, pp. 31-40. https://doi.org/10.18196/st.221234

Wirasinghe, S. C., \& Bandara, S., 1990, "Airport Gate Position Estimation for Minimum Total Costs-Approximate Closed Form Solution", Transportation Research Part B, Vol 24 No. 4, pp. 287-297. https://doi.org/10.1016/0191-2615(90)90003-H

Xiao, M., Chien, S., Schonfeld, P., \& Hu, D., 2020, "Optimizing Flight Equencing and Gate Assignment Considering Terminal configuration and walking time. Journal of Air Transport Management, Vol. $86,101816$. https:// doi.org/10.1016/j.jairtraman.2020.101816

Yocing, P., Adisasmita, S. A., \& Hustim, M., 2020, "Optimasi Model Desain Terminal Pada Bandara Menggunakan Linear Program". Core.Ac,UK. https://core.ac.uk/download/pdf/327696292.pdf 